\title{
Interdisciplinary project-based learning as a means of developing employability skills in undergraduate science degree programs
}

\author{
Joanne Hart ${ }^{1}$ \\ Corresponding author: Joanne Hart (joanne.hart@sydney.edu.au) \\ ${ }^{1}$ School of Medicine, University of Sydney
}

\begin{abstract}
Project-based learning units are often used for large scale work integrated learning (WIL) experiences in Liberal Studies Degrees as they offer scalability and sustainability of delivery to large cohorts. This systematic search and review evaluates the effectiveness of interdisciplinary project-based learning in Science Degree programs for developing discipline knowledge and employability skills. Education literature databases were searched for peerreviewed journal articles that discussed undergraduate science-based degree programs with project-based learning units involving students from multiple disciplines. Data were analysed for evidence of a skill gain in 6 areas (Discipline knowledge, Communication, Teamwork, Interdisciplinary effectiveness, Critical thinking and problem solving, and Self-management). Projects were assigned to categories based on interdisciplinary breadth and depth. Data was analysed by cross-tabulations, Fisher's Exact test and by calculating odds ratios (OR), which indicate the effect size. Perception of a skill gain was significantly more likely to be reported than an objectively measured skill gain $(p<0.001)$. Real discipline skill gains were 6.6 times more likely in projects narrow in discipline mix (OR 6.6), however perceived discipline skill gains were high irrespective of project type. Projects with wide interdisciplinarity were significantly associated with perceived gains in interdisciplinary effectiveness (OR $32, p<0.05$ ) and more likely to have perceived gains in communication (OR 2.5) and teamwork (OR 3.4) skills. When projects have greater interdisciplinary breadth or depth, perceived student employability skill gains increase, perceived discipline skill gains are unaffected, however actual discipline skill gains are less reported. Further research and evidence that project-based learning is meeting the desired WIL learning objectives of the curriculum is needed
\end{abstract}

Keywords

Project-based learning, capstone project, interdisciplinary learning, undergraduate science, employability skills, curriculum design:

\section{Introduction}

Graduate employability is an important topic of interest to a range of stakeholders; employers, the Government, universities and students, and increasing employability by upscaling work integrated learning in science is a national priority (Australian Council of Deans in Science, 2016). Employers seek employees with a range of transferable skills and strong disciplinary knowledge alone, does not guarantee a new graduate a job (Crebert, Bates, Bell, Patrick, \& Cragnolini, 2004). Traditional undergraduate curricula promote a focus on discipline-specific knowledge, however employers value and seek transferable skills (Foundation for Young Australians, 2016; Lin-Stephens et al., 2017), 
including capabilities in active learning, teamwork, critical thinking and creative problem-solving (Deloitte Access Economics, 2014; Sarkar, Overton, Thompson, \& Rayner, 2016). Further, employers prefer teamwork, communication and self-management skills (Bee \& Hie, 2015; Foundation for Young Australians, 2016; Sarkar et al., 2016), above degree classification, intelligence and even the reputation of the institution the graduate attended (Leckey \& McGuigan, 1997).

Science students in particular do not appreciate the importance of employability skills in professional science-based occupations (Harris, 2012), or that these skills are useful in academic and research careers as well as in employment in other sectors. In Australia, science degree graduates struggle to get their first job, this includes both the physical and life sciences. A recent study showed that only $51 \%$ of the science graduates looking for full-time work had found it four months after completing their degree (Norton, 2016) and science graduates have poorer full-time employment outcomes immediately upon graduation compared with vocationally trained disciplines (Qualities Indicators for Learning and Teaching (QILT), 2018). In addition, science graduates are destined to work in a wide range of occupations; only $20 \%$ of BSc graduates in Australia will be working in traditional science jobs (Palmer, Campbell, Johnson, \& West, 2017). Furthermore, the future of all types of work is uncertain. Big changes are expected in employment in the medium term; occupations are changing, some are disappearing, others not yet conceived (Innovation and Science Australia, 2017; World Economic Forum, 2018). Thus, we need to prepare our students for the contemporary workforce. It is therefore necessary to ensure balance between discipline knowledge and addressing the broader knowledge and skills our students will need for their future work (Palmer et al., 2017). The popular concept of the 'T shaped' person (Johnston, 1978) is now outdated and having one in-depth disciplinary skill is no longer sufficient. Instead the 'key' shaped individual that has cross disciplinary experience of varying depths that supports and complements their breadth and ability to integrate knowledge and collaborate (Bridgestock, 2015; Diodati, 2017) is the model for the future, and big data can be employed to analyse the job skills employers need most.

Traditional work integrated learning (WIL) placements, practicums or internships where students work in a professional environment are not practical for large student cohorts and traditionally not used in science degrees. Thus, many science degree programs adopt 'non-placement WIL' where students may participate in work-based, capstone projects, or simulations, with or without external partners. The 'capstone project' model provides opportunities to develop employability skills and offers scalability and sustainability of offering.

Project-based learning is known to be effective for facilitating knowledge acquisition and retention, supporting the development of important real-world skills such as solving complex problems, thinking critically, analysing and evaluating information, working cooperatively, and communicating effectively and for developing flexible knowledge (see (English \& Kitsantas, 2013)). In addition, there are reported benefits of working in integrated and interdisciplinary teams. Modern, complex problems cut across discipline boundaries, thus to reach a more comprehensive explanation of complex, real-life problems, insights from several disciplines need to be reconciled and integrated (de Greef, Post, Vink, \& Wenting, 2017). In addition, there is extensive evidence of better learning outcomes with 'active learning' teaching methods (Freeman et al., 2014). Inquiry based learning with problem finding and solving in a collaborative project is motivational and fosters cognitive engagement (Blumenfeld et al., 1991). Overall, the inclusion of project-based learning in the curriculum is designed to foster the attainment of the graduate qualities, improve employability and increase engagement and application of discipline knowledge.

While there is a widespread use of capstone project-based learning units in various delivery modes in science degree programs there has been little study of the effectiveness of these study units in driving attainments in discipline skills or knowledge or in the development of employability skills. The aim of this study is to investigate any association between the interdisciplinary nature of capstone-type projects offered and learning outcomes for both discipline-based skills and

Hart, J. (2019). Interdisciplinary project-based learning as a means of developing employability skills in undergraduate science degree programs. Journal of Teaching and Learning for Graduate Employability, 10(2), 50-66. 
employability skills including communication, teamwork, interdisciplinary effectiveness, critical thinking and problem solving and self-management skills.

The research questions were:

1. Do interdisciplinary project units deliver on learning outcomes of discipline-based skill development and employability skill development?

2. Is the breadth and/or depth of the interdisciplinary experience in project units associated with better learning outcomes?

The overall objective of the study is to provide data to drive evidence-based curriculum developments that will result in more skilled and employable science graduates.

\section{Methods}

This study is a systematic search and review (Grant \& Smith, 2018) of the literature on interdisciplinary project units of study offered in science and science-based degrees.

\section{Literature search strategy}

For this review A+ education, EBSCO education, ERIC and ProquestC databases were searched using the terms: science (OR math*, chemistry, physics, psychology, geology) AND project-based learning (OR student projects, capstone projects, projects) AND interdisciplinary (OR multidisciplinary, cross disciplinary, trans-disciplinary) AND undergraduate (OR higher education, post-secondary, college). A diagram showing the record identification, screening eligibility and inclusion process is shown in Figure 1.
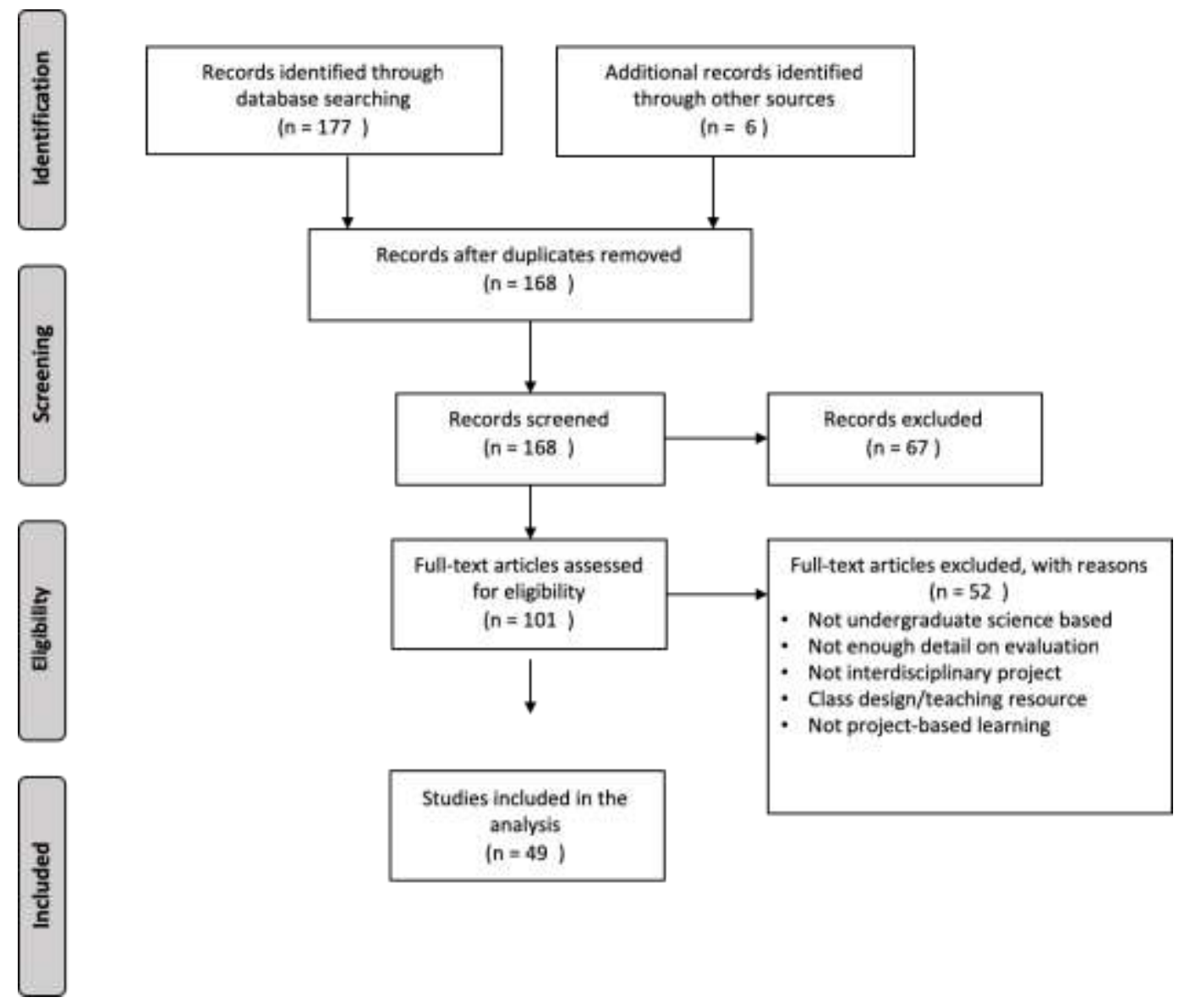

Hart, J. (2019). Interdisciplinary project-based learning as a means of developing employability skills in undergraduate science degree programs. Journal of Teaching and Learning for Graduate Employability, 10(2), 50-66. 


\section{Figure 1: Flow diagram showing the record identification, screening, eligibility and inclusion of studies for the analysis.}

The search was restricted to peer reviewed journal articles published in English from 2008 -2018. Included articles described an undergraduate project-based learning task that involved students from various disciplines, who were enrolled in a science-based degree program (Engineering, Biomedical Science and Computer Science were included). Included articles reported on outcomes of discipline-based skill development, or 'employability' skill development. Following exclusion of duplicates, many of the records were excluded as they did not provide enough detail of the outcomes sought in this review. There were many descriptive case studies that explained a novel, interesting course well, but did not evaluate the outcomes. Some records were excluded as their student projects were not 'interdisciplinary' according to our definitions, usually because they did not enrol students from multiple disciplines into the project. Background data collected from the records included country of study, study methodology, Degree Program and Year level, the disciplines involved in the project, cross Faculty partners, the length of project and student group sizes.

\section{Definitions of the project categories used in the analysis}

Information on the type of interdisciplinary project work was also collected by categorising each project described by interdisciplinary breadth and depth (Jantsch, 1970). Interdisciplinary breadth is determined by the mix of student disciplines involved in the project. It was considered in 3 categories:

1. Narrow; within discipline or combining closely related disciplines (e.g. biochemistry and molecular biology)

2. Medium; within Faculty (e.g. biology and mathematics)

3. Wide; cross Faculty (e.g. chemistry and law)

Interdisciplinary depth was determined by the project task, not by student discipline background. Projects were assigned to either:

1. Sequential tasks were where one discipline group hands over project tasks to another sequentially, essentially doing their own discipline work, with little integration of discipline skills.

2. Integrated tasks where the student teams had to work together and integrate their disciplinary skills and knowledge to undertake the project.

\section{Definitions of the skills assessed}

Skill development was divided into 'actual' and 'perceived' where actual skill development was measured objectively, usually by pre- and post-project test methods. Perceived skill development was reported by the opinion of the student or academic staff that there was an improvement in the skill and was usually assessed in a post course survey with a Likert scale (quantitative), but in some cases assessed with qualitative data coming from focus groups, open-ended survey questions, or by assessing student learning products, assignments or reflective blog posts. The list of skills developed assessed by this study were: Discipline knowledge, Communication, Teamwork, Interdisciplinary effectiveness, Critical thinking and problem solving and Self-management skills. These are based on skills that appear in online 'Top 10 Employability Skills' lists and University 'Graduate Attribute' lists (Oliver \& Jorre de St Jorre, 2018; University of Sydney, 2016). 


\section{Statistical analysis}

Data were analysed by cross-tabulation and using Fisher's (2-sided) exact test comparing the project categories with each skill development item. Odds ratios were calculated by:

$\mathrm{OR}=\frac{N 1 / W_{1}}{N 0 / W_{0}}$

Where $\mathrm{N}$ is a project with narrow interdisciplinarity and $\mathrm{W}$ is a project with wide interdisciplinarity, $0=$ no skill gain, $1=$ skill gained.

Thus, the odds ratio is a relative measure of effect allowing a comparison of groups; an odds ratio of 1 is no difference and an odds ratio of 10 is means there is 10 times the effect for one group over the other. Separate analyses were made for actual skill development and perceived skill development. $p<0.05$ was accepted as statistically significant.

\section{Background information on the included studies}

Studies included in this analysis were from a range of countries and continents, the majority from the USA (See Supplementary Data 1). As in the inclusion criteria, all studies included centred on undergraduate Bachelor of Science and Bachelor of Engineering degrees, or variations (eg Bachelor of Computer Science or Biomedical Science). Many studies did not state the student year level involved in the projects, (36\%), although there are studies from each of the 4 undergraduate years included. Some studies have mixed year levels (26\%). Most projects ran for a $\sim 12$ week semester (79\%), some as an intensive units between semesters (9\%), some ran over multiple years (4\%), some did not state the project length (8\%). Student project group sizes varied and were not always reported (47\%), though 3-5 students (40\%) was the most common group size. The science disciplines involved in project units were broad (See Supplementary Data 2). Projects running across Faculties involved a range of Faculty partners, with Humanities Faculties the most common collaborator (See Supplementary Data 3).

\section{Study types included}

The data included was heterogenous regarding the study type and the mode of project unit offering. Most of the reports were descriptive case studies (98\%), with some intentional evaluation studies (57\%). A small proportion were specifically designed educational research studies (9\%).

\section{Results}

\section{Actual vs perceived skill gains}

Most studies reported 'perceived' skill gains rather than 'actual' skill gains. This was most apparent for the employability skill items, but also quite common for discipline knowledge gains.

Table 1: Reports of actual vs perceived skill gains for the skill areas assessed in this study

\begin{tabular}{|l|c|c|}
\hline \multirow{2}{*}{ Skill } & \multicolumn{2}{|c|}{$\begin{array}{c}\text { Reports of skill gain } \\
\text { (\% of included studies) }\end{array}$} \\
\cline { 2 - 3 } & Actual & Perceived \\
\hline Discipline Knowledge & 28 & 68 \\
\hline Communication Skills & 6 & 51 \\
\hline
\end{tabular}

Hart, J. (2019). Interdisciplinary project-based learning as a means of developing employability skills in undergraduate science degree programs. Journal of Teaching and Learning for Graduate Employability, 10(2), 50-66. 


\begin{tabular}{|l|c|c|}
\hline Teamwork & 9 & 68 \\
\hline Interdisciplinary effectiveness & 6 & 60 \\
\hline Critical thinking and Problem Solving & 9 & 62 \\
\hline Self-management skills & 2 & 32 \\
\hline
\end{tabular}

\section{Discipline skill development}

Actual discipline skill gains were reported less often as the interdisciplinarity breadth of the project increased from narrow to medium (OR 2.8) and narrow to wide (OR 6.6, Fig 2A), meaning that it is 2.8 times more likely to achieve a discipline skill gain in a project with narrow compared to medium level interdisciplinarity and this extends to 6.6 times when compared to a project with wide interdisciplinarity. However, there was no difference in actual skills developed as interdisciplinary depth increased (Fig 2B). Perceived discipline skill gains were well reported and not different regardless of project interdisciplinarity breadth or depth (Fig 2C \& D).

A

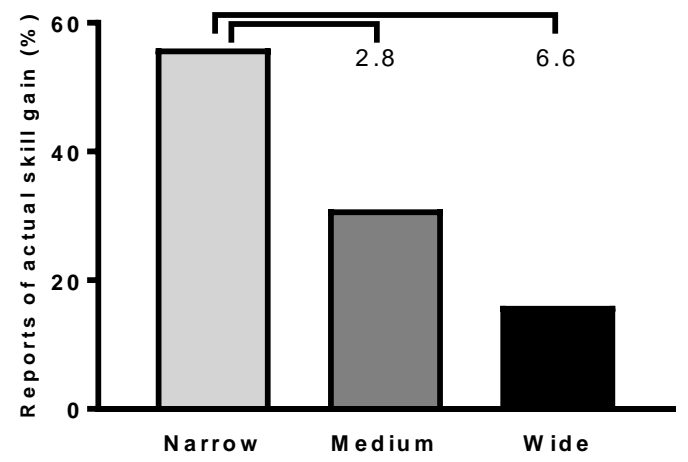

C

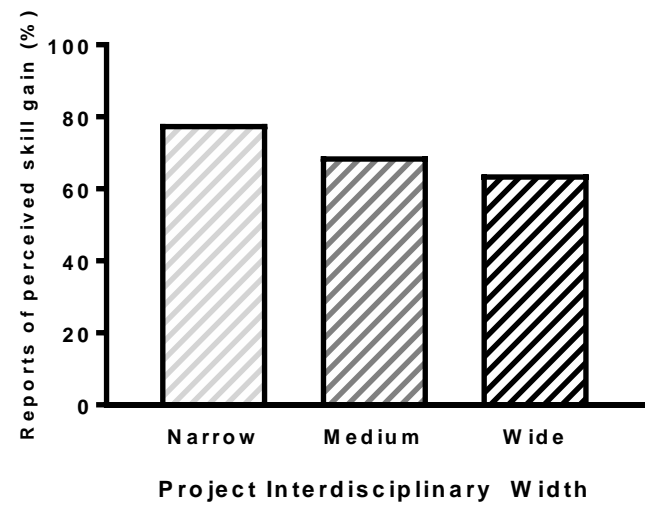

B

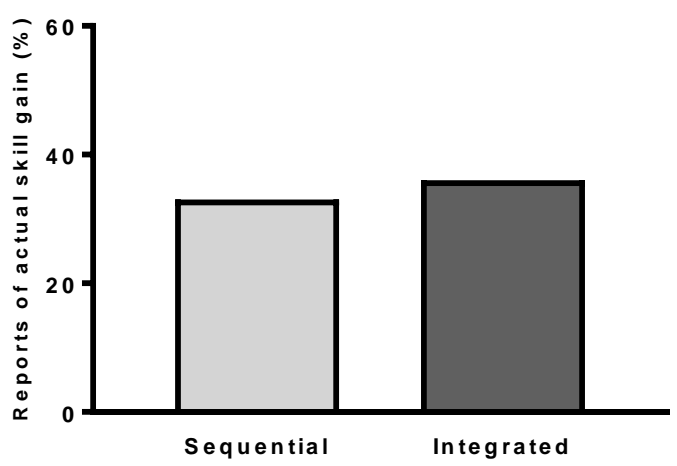

D

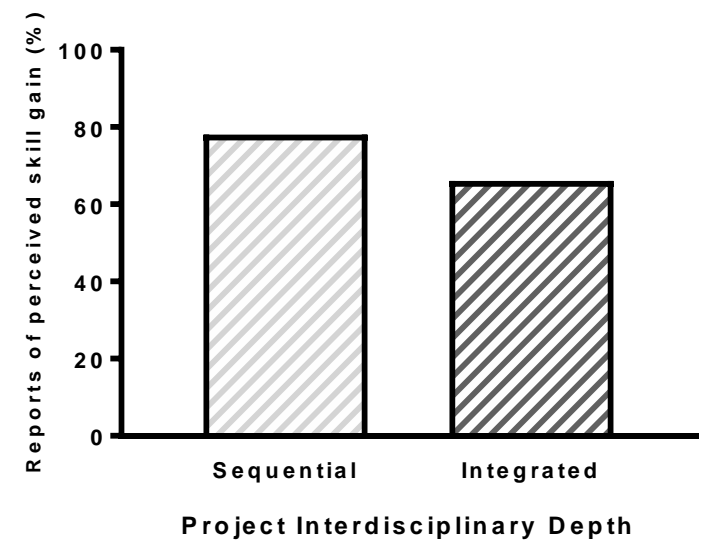

Figure 2: Positive reports of an actual discipline skill gain by $A$ interdisciplinary breadth and $B$ interdisciplinary depth. Positive reports of a perceived discipline skill gain by $C$ interdisciplinary breadth and $D$ interdisciplinary depth. Odds Ratios shown by the horizontal brackets. 


\section{Employability skill development}

\section{Communication skills}

Actual communication skill gains were reported less often as the interdisciplinarity breadth of the project increased from narrow to medium (OR 3.4, Fig 3A). There were too few reports of communication skill gains in projects with wide interdisciplinarity breadth or regarding interdisciplinary depth to be analysed (Fig 3B). Perceived communication skill gains were reported more often as interdisciplinary breadth increased (OR 2.3-2.5, Fig $3 C$ ), but otherwise not different regardless of project interdisciplinarity depth (Fig 3D).

A

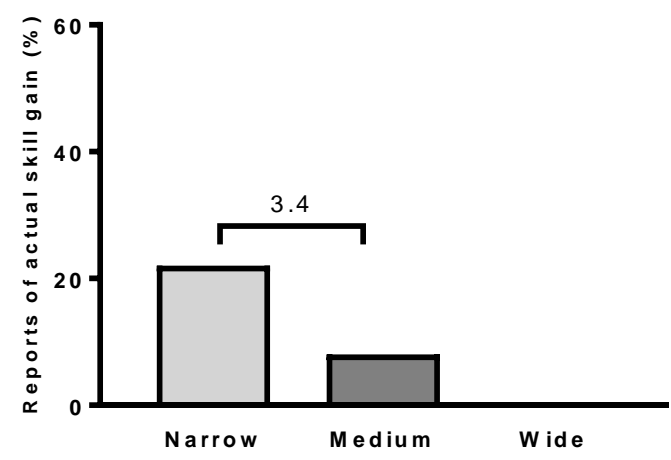

C

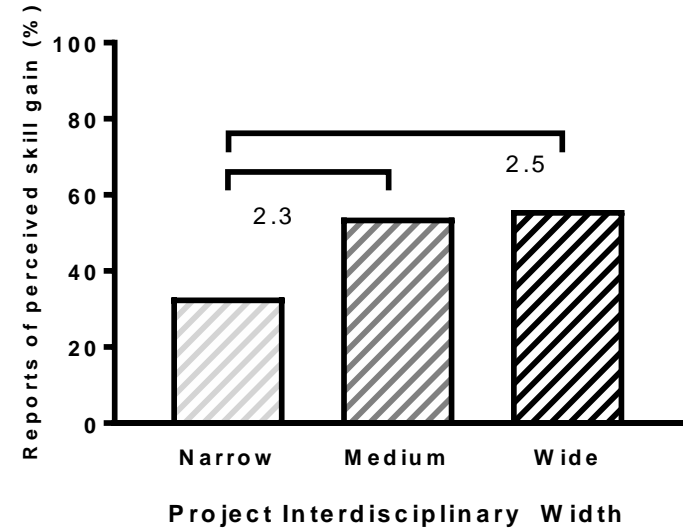

B

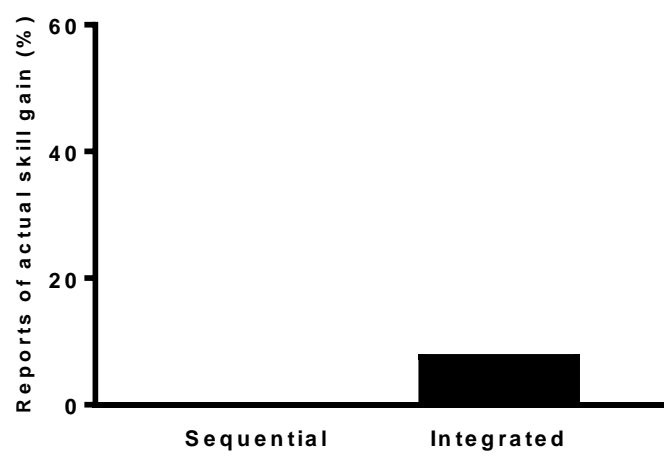

D

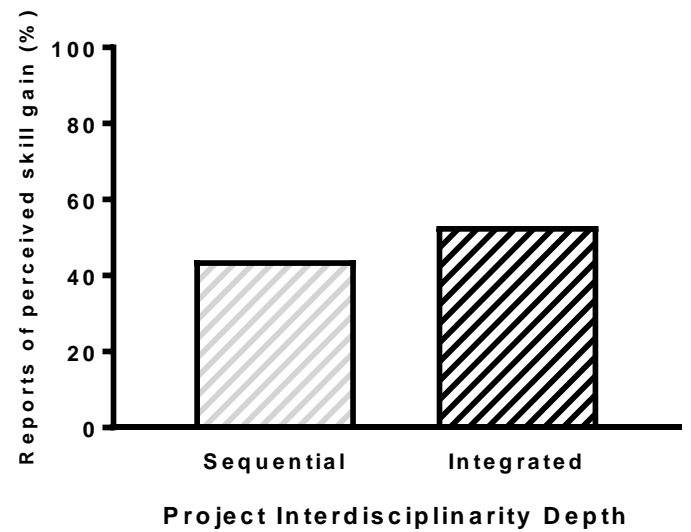

Hart, J. (2019). Interdisciplinary project-based learning as a means of developing employability skills in undergraduate science degree programs. Journal of Teaching and Learning for Graduate Employability, 10(2), 50-66. 
Figure 3: Positive reports of an actual communication skill gain by A interdisciplinary breadth and $B$ interdisciplinary depth. Positive reports of a perceived communication skill gain by $C$ interdisciplinary breadth and $D$ interdisciplinary depth. Odds Ratios shown by the horizontal brackets.

\section{Teamwork skills}

Actual teamwork skill gains were reported less often as the interdisciplinarity breadth of the project increased from narrow to medium (OR 3.4) or narrow to wide (OR 6.9, Fig 4A). There was no association between actual teamwork skill gains and interdisciplinary depth (Fig 4B). Perceived teamwork skill gains were reported more often in projects with wide interdisciplinarity (OR 3.2-3.4, Fig 4C) Perceived teamwork skill gains were not different regardless of project interdisciplinarity depth (Fig 4D).

A

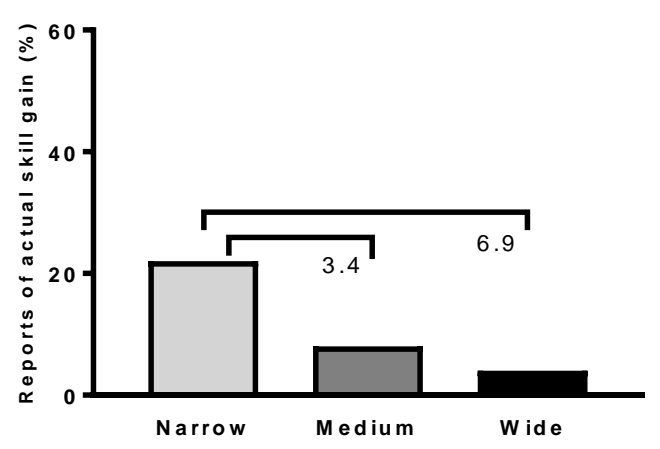

C

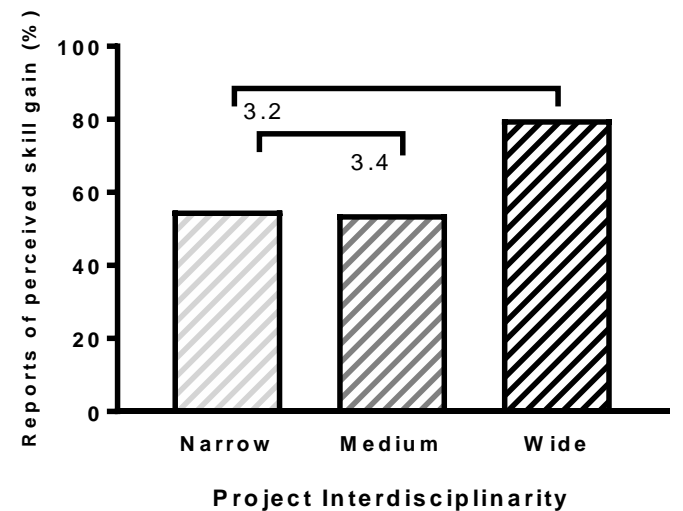

B

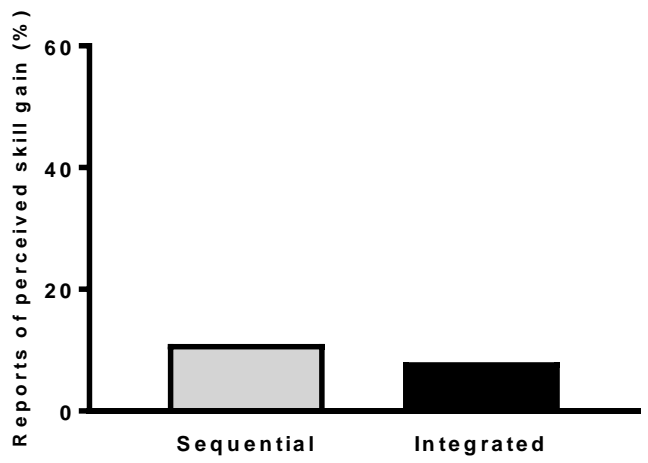

D

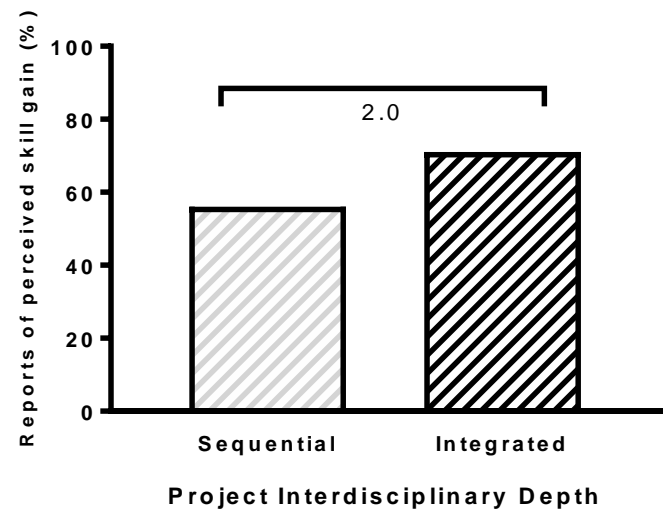

Figure 4: Positive reports of an actual teamwork skill gain by $A$ interdisciplinary breadth and $B$ interdisciplinary depth. Positive reports of a perceived teamwork skill gain by C interdisciplinary breadth and D interdisciplinary depth. Odds Ratios shown by the horizontal brackets. 


\section{Interdisciplinary effectiveness}

Actual interdisciplinary effectiveness skill gains were poorly reported and could not be analysed (Fig $5 A \& B)$. There was a significant association of a perceived gain in interdisciplinary effectiveness in projects with wide interdisciplinarity (OR 32.0, p<0.001, Fisher's exact test, Fig $5 \mathrm{C}$ ) and in projects with interdisciplinarity which required integration of discipline skills, rather than multi-disciplinary sequential tasks (OR 7.6, p<0.05, Fisher's exact test, Fig 5D).

A

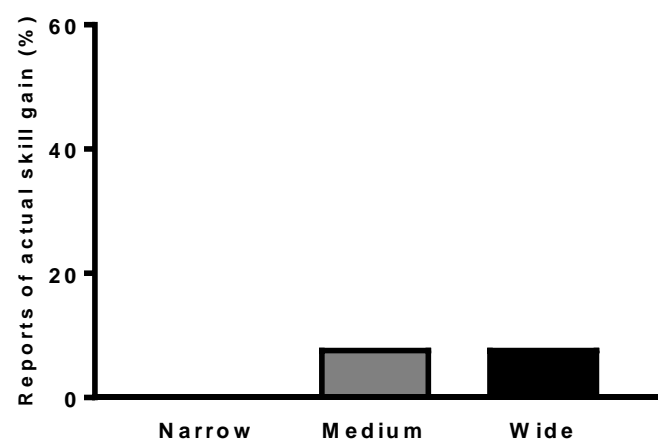

C

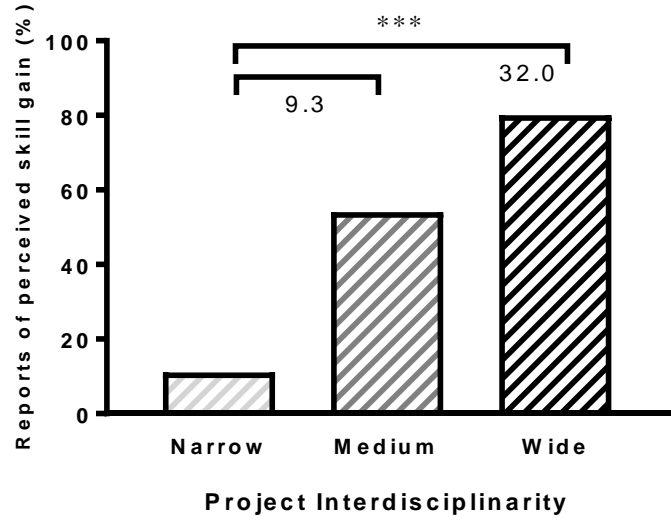

B

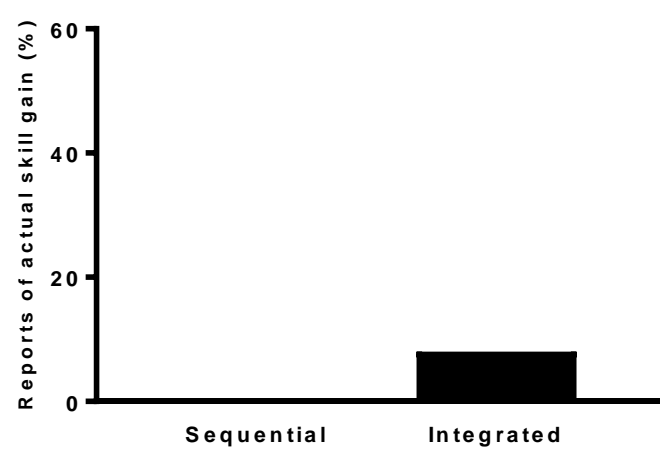

D

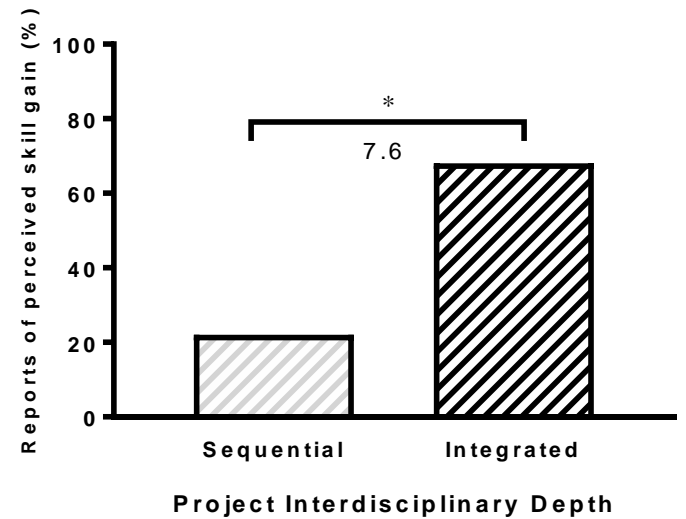

Figure 5: Positive reports of an actual interdisciplinary effectiveness skill gain by $A$ interdisciplinary breadth and $B$ interdisciplinary depth. Positive reports of a perceived interdisciplinary effectiveness skill gain by $C$ interdisciplinary breadth and $D$ interdisciplinary depth. Odds Ratios shown by the horizontal brackets. 


\section{Critical thinking and problem solving}

Actual critical thinking and problem-solving skill gains were poorly reported and could not be analysed (Fig 6A \& B). Perceived critical thinking and problem-solving skill gains were reported more often in projects with wide interdisciplinarity (OR 2.7, Fig 6C), or greater interdisciplinary depth (OR 4.3, Fig 6D).

A

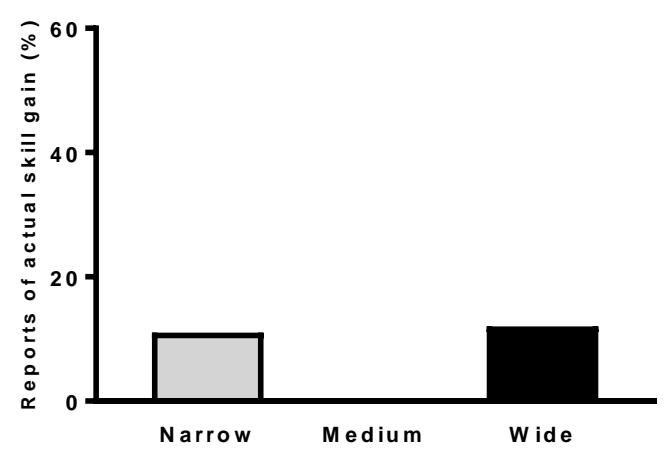

C

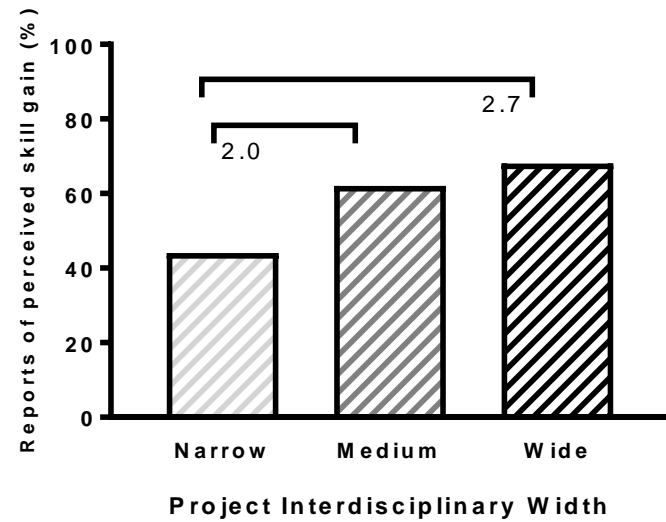

B

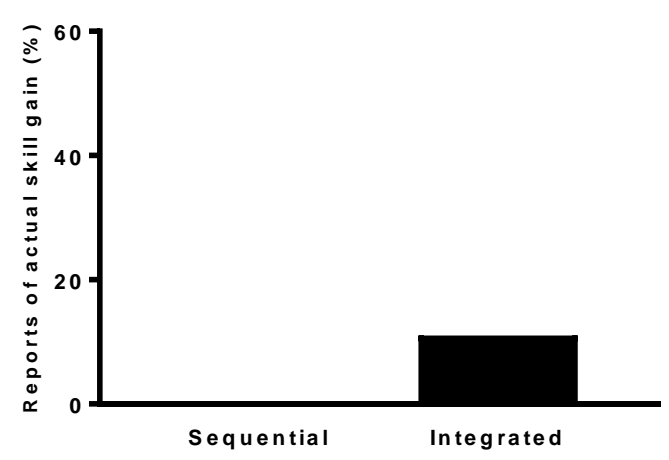

D

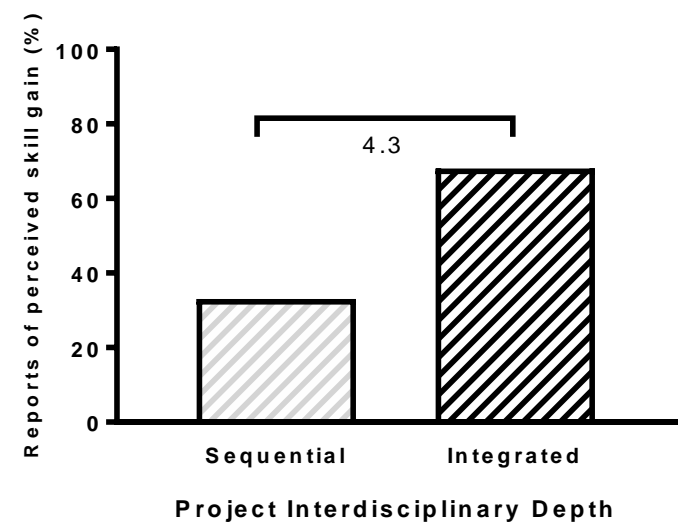

Figure 6: Positive reports of an actual problem-solving and critical thinking skill gain by $A$ interdisciplinary breadth and B interdisciplinary depth. Positive reports of a perceived problemsolving and critical thinking skill gain by $C$ interdisciplinary breadth and D interdisciplinary depth. Odds Ratios shown by the horizontal brackets. 


\section{Self-management skills}

Actual self-management skill gains were poorly reported and could not be analysed (Fig 7A \& B). Perceived self-management skill gains were reported in about a third of the projects. Perceived selfmanagement skill gains were not different regardless of project interdisciplinarity breadth or depth (Fig 7C \& D).

A

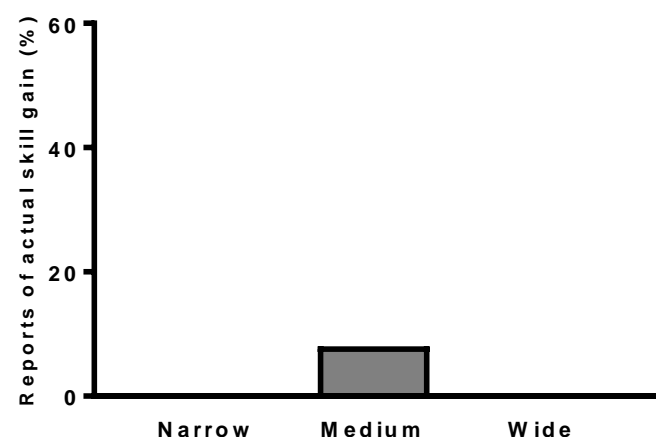

C

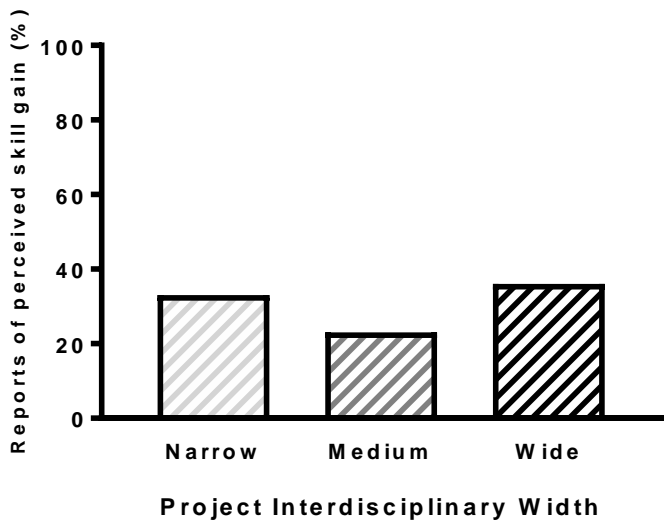

B

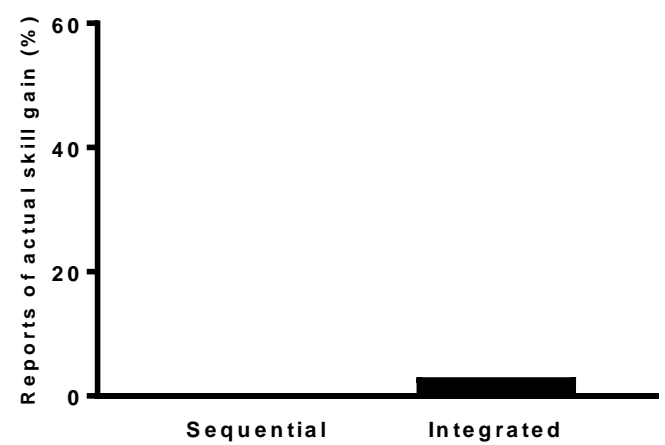

D

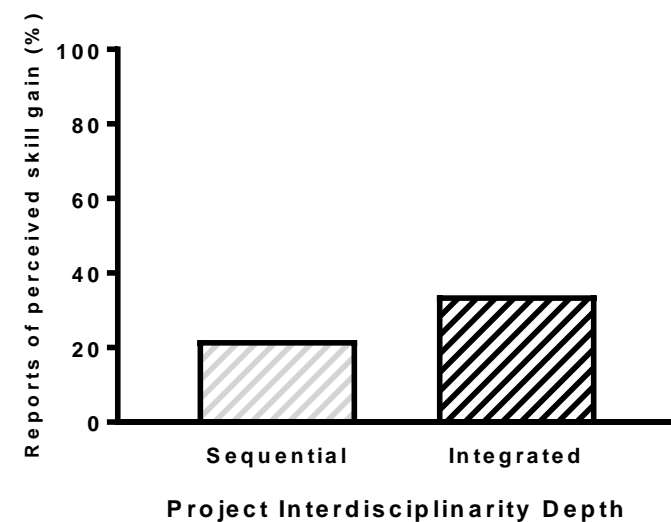

Figure 7: Positive reports of an actual self-management skill gain by A interdisciplinary breadth and $B$ interdisciplinary depth. Positive reports of a perceived self-management skill gain by $C$ interdisciplinary breadth and $D$ interdisciplinary depth. Odds Ratios shown by the horizontal brackets.

\section{Discussion}

This study is the first to apply a systematic search and review of the reporting of student skill gains attained in interdisciplinary project-based learning units that are offered in science degree 
programs. The aim was to investigate an association between the interdisciplinary nature of capstone-style project units offered and learning outcomes for both discipline-based skills and employability skills. The findings of the study can be summarised into 3 main themes:

1. The assessment of actual vs perceived skill gains,

2. Discipline-based skill gains; and

3. Overall employability skill development in interdisciplinary project-based learning units.

The first and very clear finding of this study is that there is a large gap between reporting of actual skill gains and self-reported, perceived skill gains. Skill gains reported in the literature were not often objectively measured, however student perceptions of their learning were frequently described, mostly by self-reports of skills gains using Likert scale surveys. This problem of actual vs perceived skill gains is a methodological limitation of much of the published literature in this area. Objective assessments for employability skills do exist but were not widely adopted in the studies assessed here. There are published strategies for assessing attainment of skills such as communication (Moni, Hryciw, Poronnik, \& Moni, 2007), teamwork (Riebe, Roepen, Santarelli, \& Marchioro, 2010) and critical thinking (Abrami et al., 2015), however skills such as interdisciplinary effectiveness, creativity, self-management and motivation are more difficult to objectively assess. The obvious problem with measuring perceived competence is that it may or may not equate with actual competence. There are studies that show positive alignment between perceived and actual competence (Kuhn \& Rundle-Thiele, 2009) but also studies that maintain the opposite (DiPiro, 2010). The results from this study show that reports of actual discipline-skill gains decrease whilst reports of perceived disciplineskills increase, very few studies reported both. Without a study design that deliberately measures both for a comparison, we cannot know if perceived competence equates with true competence in a skill.

An intriguing, but perhaps unsurprising finding from this study is a reduction in the reporting of actual discipline skill development as the interdisciplinarity of the project offered increases. Unsurprising as the interdisciplinary project offering is likely to focus less on discipline skills and more on employability skills by its very nature. Intriguing as a loss of discipline content is the primary fear of academic staff as more project-based learning is introduced into curricula, taking up credit points previously owned by the discipline, and teaching staff are also required to deliver on employability learning outcomes that they may feel ill prepared to deliver (Chadha, 2006). Thus, the present study confirms those concerns of academic staff.

Another important finding is that perceived discipline gains were not different regardless of project interdisciplinary breadth or depth. The students think they are achieving discipline skill gains in interdisciplinary project units that are not matched by the actual skill development data. The positive aspect of this finding is that a broad range of project offerings will be capable of supporting discipline skill development. However, future interdisciplinary project units will need careful assessment plans to ensure that discipline skills gains are real.

The timing of the capstone project experience is also important for development of the disciplinebased skills. If the project unit is delivered prior to or early in the final year of study then students may not have completed all discipline content units that contribute to their major, thus are not truly discipline experts at the time they undertake the project unit. On the other hand, identifying what they don't know, and need to know about their discipline to contribute to a project is an effective way to encourage self-directed learning.

Self-management skills and ability and willingness to learn has been shown to be highly desired by employers and by new graduates who see the importance of being adaptable (Coll \& Zegwaard, 2006), however these skills were poorly assessed in interdisciplinary projects, including perceived gains in this skill. Communication, teamwork and critical thinking and problem solving were the most reported employability skills with actual assessments. Remarkably, the reports of actual skill

Hart, J. (2019). Interdisciplinary project-based learning as a means of developing employability skills in undergraduate science degree programs. Journal of Teaching and Learning for Graduate Employability, 10(2), 50-66. 
development for each of these drops as interdisciplinary breadth increases, however the perceived skill gains increase as interdisciplinary breadth and depth increases. Interestingly, where a skill was highlighted for development; the best example in this study is interdisciplinary effectiveness which is assumed to be developed by participating in an 'interdisciplinary project', the perceived gains in that skill were significantly greater. The students expect that they will have to interact with others from different disciplines and expect to have to think differently about the project problem. This is in line with evidence that communicating to students what they should be learning enables greater gains in that skill (Hill, Overton, Thompson, Kitson, \& Coppo, 2019; Jorre de St Jorre \& Oliver, 2018) and it is the first step in scaffolding the development of a skill. On the other hand, objectively assessing a gain in interdisciplinary effectiveness is difficult and effective assessments of this need to be developed to validate the perceived gains. This skill also needs scaffolding; it will not be enough to mix up groups of students from different backgrounds and expect them to effectively integrate their discipline skills in a meaningful way as they work on a project.

Employability skills are not taught by traditional or didactic means, they must be gained experientially, and they develop over time. The active learning approaches taken in the projectbased learning units are a positive step and provide a place to learn these skills where work placements are not feasible. However, it is not reasonable to expect that students will learn these skills simply by immersion in a project. There is good evidence that explicit instruction is required to scaffold the learning of these skills (Grant \& Smith, 2018; Moni et al., 2007). It follows that a problem with relying on a capstone unit of study to deliver the opportunity to learn these skills is the timeframe. There is evidence that positive gains can be made for critical thinking skills in science classes in one semester (Gasper \& Gardner, 2013; Gottesman \& Hoskins, 2013) however the single semester time-frame may not be optimal or realistic for the development of critical thinking skills (Grant \& Smith, 2018), or indeed other employability skills. Ideally, employability skills will be embedded throughout the curriculum. The recent adoption of curriculum mapping, from unit of study through to the degree program level in tertiary education institutions, is a means by which employability skill development can be delivered and become part of the overall picture of the program of study (Atif, Richards, Busch, \& Bilgin, 2015).

The list of skills assessed in this study is not exhaustive, indeed skills such as cultural competence, or digital literacy, were rarely mentioned in interdisciplinary project-based learning units, so there is scope for further assessment of a broader range of employability skill gains. In practice, many of the employability skills listed are not used independently. Often in the workplace they will cross over; for example teamwork and presentation skills are often required together, so assessing them individually may not reflect how the skills will be used.

The development of employability skills is generally seen as a development of transferrable skills and indeed they are often referred to as such. However, are these skills general and applicable across disciplines, and it this true of all the skills we include in employability skills lists? It is often thought that critical thinking proficiency is general, applicable across disciplines and can be tested in this general context (Ennis, 1989), however others say critical thinking mastery improves if developed and assessed within the context of the discipline (McPeck, 1990). This suggests that interdisciplinary projects would be less useful in developing discipline-related critical thinking skills than projects that have a specific discipline context. Perhaps there is a place for discipline-focussed projects that may provide an opportunity to develop employability skills in context. Further research needs to be undertaken to assess this.

\section{Limitations}

There are several limitations to this study that must be duly acknowledged. The methods used to identify appropriate literature and extract data from the studies is as rigorous as possible, described in detail and includes an assessment of publication quality, however it does fall short of a full systematic review of the area. A primary limitation of this study is the quality of the published

Hart, J. (2019). Interdisciplinary project-based learning as a means of developing employability skills in undergraduate science degree programs. Journal of Teaching and Learning for Graduate Employability, 10(2), 50-66. 
studies in which it is based. Of concern is the lack of reporting of objective assessment of all skills in project-based units of study. There is clear room for improvement in the alignment of learning objectives and assessment of project-based learning units. Bias in publication is another issue with this work, as negative studies are unlikely to be published and not all academic staff are motivated enough to publish positive findings from their work. The studies included here are published by a dedicated sub-set of academic staff.

\section{Conclusion}

The findings from this study have important implications for design and delivery of interdisciplinary project units as a scalable and sustainable method of WIL delivery:

- Liaising and collaboration with employer groups is essential to ensure graduates have skills needed for employment.

- Course directors should embrace curriculum mapping and the embedding of employability skills throughout the degree program.

- Project-based units of study have the potential to deliver on the development of multiple employability skills. Constructive alignment is paramount here, clear learning objectives and explicit teaching and assessment of employability skills are required in units that are to deliver employability skill outcomes.

- Developing practical and effective methods of assessing employability skills, thus reinforcing to students the importance of developing these skills.

- Encouraging academic staff to embed and teach employability skills into the curriculum, and supporting them to make the necessary curriculum changes is critical.

- This study shows that the mode of project delivery is not important, however adding an interdisciplinary element to project work improves the perceived gains in employability skills. Improvements in assessment practices will build on this gain.

- Longitudinal studies that address the employability outcomes associated with undergraduate teaching methods and employability curricula are required to evaluate the overall effectiveness.

In conclusion, interdisciplinary project-based learning in capstone units is used to develop employability skills. Increased interdisciplinarity of these project offerings results in decreased discipline knowledge gains but increased perceived employability skill gains. These results confirm the concerns of many academics that discipline content is sacrificed for the development of employability skills, however this need not be the case if the curriculum design follows constructive alignment (Biggs \& Tang, 2007) and the assessment plan is well devised. Skill gains can be best supported by clearly defining the employability outcomes desired and aligning these with explicit instruction and robust assessment tasks. Further research in this area is warranted to ensure there is evidence that interdisciplinary project-based learning is meeting the desired graduate employability outcomes of the curriculum

\section{Acknowledgements}

I wish to acknowledge the assistance of the Academic Liaison Librarian for the Sydney School of Education and Social Work, Ms Christine Tennant for her expert guidance with the search strategy for this study. I am very grateful for the inspiration, advice and support given by Assoc Prof Racheal Hains-Wesson (University of Sydney Business School) and Dr Elisa Bone (Faculty of Science) as the project developed. 


\section{References}

Abrami, P. C., Bernard, R. M., Borokhovski, E., Waddington, D. I., Wade, C. A., \& Persson, T. (2015). Strategies for teaching students to think critically: A meta-analysis. Review of Educational Research, 85(2), $275-314$. doi:10.3102/0034654314551063

Atif, A., Richards, D., Busch, P., \& Bilgin, A. (2015). Assuring graduate competency: A technology acceptance model for course guide tools. Journal of Computing in Higher Education, 27(2), 94-113. doi:10.1007/s12528-015-9095-4

Australian Council of Deans in Science. (2016). WIL in Science: Leadership for WIL. Final report 2016. Retrieved from https://www.chiefscientist.gov.au/wp-content/uploads/WIL-in-Science-project-report-2016-finalpublication-post-review.pdf

Bee, O. K., \& Hie, T. S. (2015). Employers' emphasis on technical skills and soft skills in job advertisements. The English Teacher, 44(1), 1-XI.

Biggs, J., \& Tang, C. (2007). Teaching for quality learning at university (3rd Edition ed.): Open University Press.

Blumenfeld, P. C., Soloway, E., Marx, R. W., Krajcik, J. S., Guzdial, M., \& Palincsar, A. (1991). Motivating projectbased learning - sustaining the doing, supporting the learning. Educational Psychologist, 26(3-4), 369398. doi:DOI 10.1207/s15326985ep2603\&4_8

Bridgestock, R. (2015). KEY-shaped people, not T-shaped people - disciplinary agility and 21st century work. Retrieved from http://www.futurecapable.com/?p=102

Chadha, D. (2006). A curriculum model for transferable skills development. Engineering Education, 1(1), 19-24. doi:10.11120/ened.2006.01010019

Coll, R., \& Zegwaard, K. (2006). Perceptions of desirable graduate competencies for science and technology new graduates. Research in Science \& Technological Education, 24(1), 29-58. doi:10.1080/02635140500485340

Crebert, G., Bates, M., Bell, B., Patrick, C., \& Cragnolini, V. (2004). Developing generic skills at university, during work placement and in employment: graduates' perceptions. Higher Education Research \& Development, 23(2), 147-165.

de Greef, L., Post, G., Vink, C., \& Wenting, L. (2017). Designing interdisciplinary education: A practical handbook for university teachers: Amsterdam University Press.

Deloitte Access Economics. (2014). Australia's STEM workforce: A survey of employers. Office of the Chief Scientist, Australia.

Diodati, M. (2017). Is being a 'T-shaped' person still enough? Retrieved from https://medium.com/re-write/isbeing-a-t-shaped-person-still-enough-2d0b43073285

DiPiro, J. (2010). Student learning: Perception versus reality. American journal of pharmaceutical education, 74(4), 1-63.

English, M. C., \& Kitsantas, A. (2013). Supporting student self-regulated learning in problem- and project-based learning. Interdisciplinary Journal of Problem-Based Learning, 7(2), 6.

Ennis, R. (1989). Critical thinking and subject specificity: Clarification and needed research. Educational Researcher, 18(3), 4-10. doi:10.3102/0013189X018003004

Foundation for Young Australians. (2016). The new basics: Big data reveals the skills young people need for the New Work Order. Retrieved from file://C:/Users/Study/AppData/Local/Temp/The-NewBasics_Update_Web.pdf

Freeman, S., Eddy, S. L., McDonough, M., Smith, M. K., Okoroafor, N., Jordt, H., \& Wenderoth, M. P. (2014). Active learning increases student performance in science, engineering, and mathematics. Proceedings of the National Academy of Sciences of the United States of America, 111(23), 8410-8415. doi:10.1073/pnas.1319030111

Gasper, B., \& Gardner, S. (2013). Engaging students in authentic microbiology research in an introductory biology laboratory course is correlated with gains in student understanding of the nature of authentic research and critical thinking. Journal of Microbiology \& Biology Education, 14(1). doi:10.1128/jmbe.v14i1.460

Gottesman, A., \& Hoskins, S. (2013). CREATE Cornerstone: Introduction to scientific thinking, a new course for STEM-interested freshmen, demystifies scientific thinking through analysis of scientific literature. CBELife Sciences Education, 12(1), 59-72. doi:10.1187/cbe.12-11-0201

Grant, M., \& Smith, M. (2018). Quantifying assessment of undergraduate critical thinking. Journal of College Teaching \& Learning (TLC), 15(1), 27-38. doi:10.19030/tlc.v15i1.10199

Harris, K. (2012). A background in science: What science means for Australian society. Retrieved from https://eric.ed.gov/?id=ED537994

Hart, J. (2019). Interdisciplinary project-based learning as a means of developing employability skills in undergraduate science degree programs. Journal of Teaching and Learning for Graduate Employability, 10(2), 50-66. 
Hill, M., Overton, T., Thompson, C., Kitson, R., \& Coppo, P. (2019). Undergraduate recognition of curriculumrelated skill development and the skills employers are seeking. Chemistry Education Research and Practice. doi:10.1039/C8RP00105G

Innovation and Science Australia. (2017). 2030 Strategic Plan for the Australian Innovation, Science and Research System. Retrieved from https://consult.industry.gov.au/office-of-innovation-and-scienceaustralia/2030-strategic-plan-for-the-australian-innovation/

Jantsch, E. (1970). Inter-disciplinary and transdisciplinary university - systems approach to education and innovation. Policy Sciences, 1(4), 403-428. doi:Doi 10.1007/Bf00145222

Johnston, D. L. (1978). Scientists become managers-the ' $T$ '-shaped man. IEEE Engineering Management Review, 6(3), 67-68. doi:10.1109/EMR.1978.4306682

Jorre de St Jorre, T., \& Oliver, B. (2018). Want students to engage? Contextualise graduate learning outcomes and assess for employability. Higher Education Research \& Development, 37(1), 44-57. doi:10.1080/07294360.2017.1339183

Kuhn, K., \& Rundle-Thiele, S. (2009). Curriculum alignment: Exploring student perception of learning achievement measures. International Journal of Teaching and Learning in Higher Education, 21(3), 351361.

Leckey, J. F., \& McGuigan, M. A. (1997). Right tracks-wrong rails: The development of generic skills in higher education. Research in Higher Education, 38(3), 365-378.

Lin-Stephens, S., Smith, S., Richards, D., Pang, V., Uesi, J., \& Athanasou, J. (2017). Students and employers don't see eye to eye: The case of information systems, information technology and engineering. PACIS 2017 Proceedings, 120.

McPeck, J. (1990). Critical thinking and subject specificity: A reply to Ennis. Educational Researcher, 19(4), 1012. doi:10.3102/0013189X019004010

Moni, R., Hryciw, D., Poronnik, P., \& Moni, K. (2007). Using explicit teaching to improve how bioscience students write to the lay public. Advances in Physiology Education, 31(2), 167-175. doi:10.1152/advan.00111.2006

Norton, A. (2016). Mapping Australian higher education 2016. Grattan Institute.

Oliver, B., \& Jorre de St Jorre, T. (2018). Graduate attributes for 2020 and beyond: Recommendations for Australian higher education providers. Higher Education Research \& Development, 37(4), 821-836. doi:10.1080/07294360.2018.1446415

Palmer, S., Campbell, M., Johnson, E., \& West, J. (2017). Occupational outcomes for Bachelor of Science graduates in Australia and implications for undergraduate science curricula. Reseach in Science Education. doi:10.1007/s11165-016-9595-x

Qualities Indicators for Learning and Teaching (QILT). (2018). 2017 Graduate Outcome Survey. Canberra, Australia: Australian Government. Department of Education and Training.

Riebe, L., Roepen, D., Santarelli, B., \& Marchioro, G. (2010). Teamwork: Effectively teaching an employability skill. Education + Training, 52(6/7), 528-539. doi:10.1108/00400911011068478

Sarkar, M., Overton, T., Thompson, C., \& Rayner, G. (2016). Graduate employability: Views of recent science graduates and employers. International Journal of Innovation in Science and Mathematics Education, 24(3), 31--48.

University of Sydney (2016). 2016-2020 Strategic Plan. Sydney: University of Sydney.

World Economic Forum (2018). The future of jobs report 2018. World Economic Forum.

Supplementary data

Hart, J. (2019). Interdisciplinary project-based learning as a means of developing employability skills in undergraduate science degree programs. Journal of Teaching and Learning for Graduate Employability, 10(2), 50-66. 


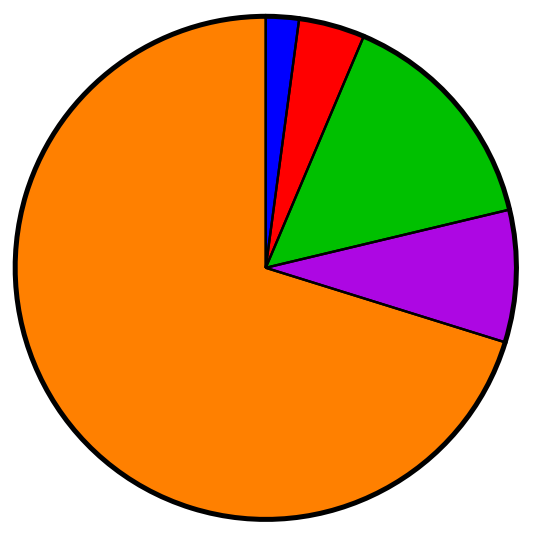

Asia

Australia-Pacific

Europe

Middle East

Nth America

S1. Region of origin of the reports included in this study.

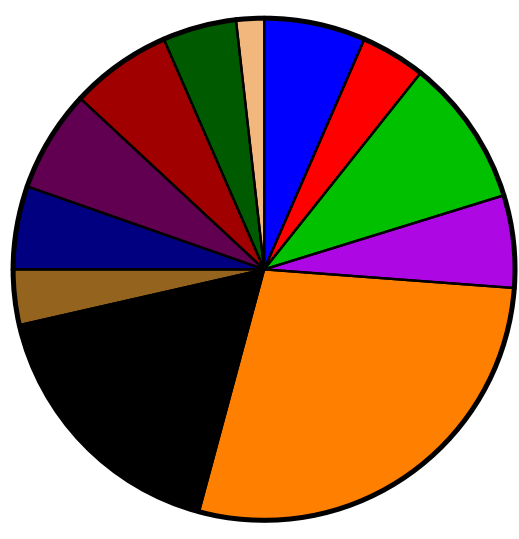

$\square$ Chemistry
$\square$ Physics
$\square$ Biology
$\square$ Mathematics and Statistics
Engineering
Computer sciences
$\square$ Earth Sciences
$\square$ Environmental science
$\square$ Medical sciences
$\square$ Pealth Sciences
$\square$ Psychology
$\square$ Other

S2. Science disciplines involved in the interdisciplinary projects included in this study.

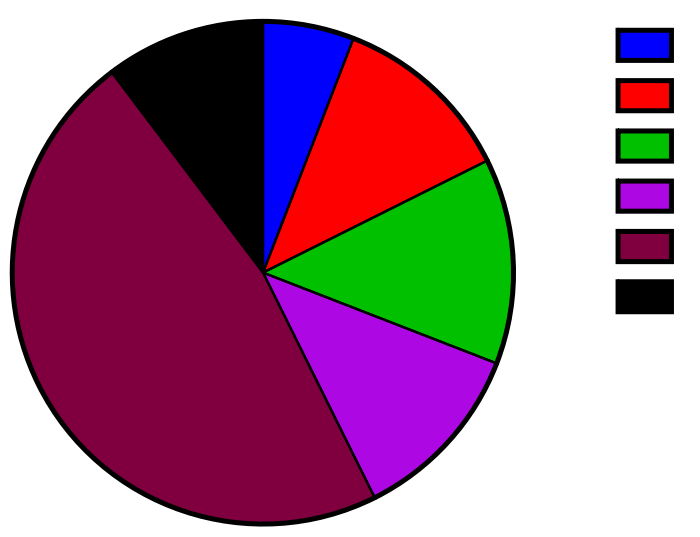

Architecture and Design

Arts (visuals/performing)

Business and Marketing

Education

Humanities

Law 
S3. Non-science Faculties involved in the interdisciplinary projects included in this study.

Hart, J. (2019). Interdisciplinary project-based learning as a means of developing employability skills in undergraduate science degree programs. Journal of Teaching and Learning for Graduate Employability, 10(2), 50-66. 